\title{
Consequences of frugivore-mediated seed dispersal for the spatial and genetic structures of a neotropical palm
}

\author{
J. CHOO, ${ }^{*}$ T. E. JUENGERt and B. B. SIMPSON† \\ *Department of Ecology and Evolutionary Biology, University of Michigan, Ann Arbor, MI 48109, USA, +Section of Integrative \\ Biology, The University of Texas at Austin, 1 University Station CO930, Austin, TX 78712, USA
}

\begin{abstract}
The idiosyncratic behaviours of seed dispersers are important contributors to plant spatial associations and genetic structures. In this study, we used a combination of field, molecular and spatial studies to examine the connections between seed dispersal and the spatial and genetic structures of a dominant neotropical palm Attalea phalerata. Field observation and genetic parentage analysis both indicated that the majority of A. phalerata seeds were dispersed locally over short distances $(<30 \mathrm{~m}$ from the maternal tree). Spatial and genetic structures between adults and seedlings were consistent with localized and short-distance seed dispersal. Dispersal contributed to spatial associations among maternal sibling seedlings and strong spatial and genetic structures in both seedlings dispersed near $(<10 \mathrm{~m})$ and away $(>10 \mathrm{~m})$ from maternal palms. Seedlings were also spatially aggregated with juveniles. These patterns are probably associated with the dispersal of seeds by rodents and the survival of recruits at specific microsites or neighbourhoods over successive fruiting periods. Our cross-cohort analyses found palms in older cohorts and cohort pairs were associated with a lower proportion of offspring and sibling neighbours and exhibited weaker spatial and genetic structures. Such patterns are consistent with increased distance- and density-dependent mortality over time among palms dispersed near maternal palms or siblings. The integrative approaches used for this study allowed us to infer the importance of seed dispersal activities in maintaining the aggregated distribution and significant genetic structures among A. phalerata palms. We further conclude that distance- and density-dependent mortality is a key postdispersal process regulating this palm population.
\end{abstract}

Keywords: genetic structure, palms, plant-frugivore interactions, seed dispersal, spatial patterns

Received 6 April 2011; revision received 16 November 2011; accepted 18 November 2011

\section{Introduction}

Seed dispersal is an important life history event for plants and has consequences from genes to communities (Nathan \& Muller-Landau 2000). Dispersal contributes to plant gene flow and is a key mechanism that generates the genetic structure of plant populations (Hamrick et al. 1993b). For many tropical plant species, dispersal is also critical to plant recruitment and regeneration because undispersed propagules suffer high rates of mortality near conspecific adults (distance-

Correspondence: Juanita Choo, Fax: 1734763 0544;

E-mail: juanchoo@umich.edu dependent mortality) (Terborgh et al. 2008; Swamy \& Terborgh 2010) or under high conspecific densities (density-dependent mortality) (Harms et al. 2000; Comita \& Hubbell 2009; Bagchi et al. 2010; Metz \& Sousa 2010). These patterns of mortalities were proposed to be important factors that contributed to the diversity of tropical tree communities (Janzen 1970; Connell 1971).

Most tropical plant species are dispersed by vertebrate frugivores, and many of them exhibit idiosyncratic behaviours unique to their species or guild (Howe \& Smallwood 1982; Terborgh 1990). Tropical birds, for instance, frequently disperse seeds under trees where they roost or forage (Clark et al. 2004; Sezen et al. 2007). Rodents, including agoutis and 
squirrels, habitually disperse and cache seeds near the trunks and buttress roots of specific plants or reference objects such as fallen logs (Heaney \& Thorington 1978; Smythe 1978; Forget 1990; Peres \& Baider 1997; Forget et al. 1999; Silvius \& Fragoso 2003; Pimentel \& Tabarelli 2004; Aliaga-Rossel et al. 2008; Haugaasen et al. 2010). Nonrandom dispersal activities contribute not only to specific patterns of recruitment but also to distinct spatial genetic structures (SGSs) (Clark et al. 2004, 2005; Russo \& Augspurger 2004; Sezen et al. 2009; Karubian et al. 2010). These spatial and genetic patterns in turn affect the intensity of ecological interactions and the evolutionary dynamics of plant populations (Hardy et al. 2006; Comita \& Hubbell 2009). Studying how seed dispersers influence plant spatial and genetic patterns is thus an important step towards understanding their role in plant population dynamics and species coexistence (Levine \& Murrell 2003; Snyder \& Chesson 2003).

To infer the proximate and ultimate consequences of vertebrate frugivore seed dispersal on tropical plant populations, studies should ideally track the fate of dispersed seeds over their lifetimes as well as changes in the plant spatial and genetic patterns. However, such studies are intractable for many tropical plant species that are long-lived and slow-growing. To overcome this problem, a combination of approaches including direct observations of seed dispersal and studies of plant spatial and genetic structures can be applied to understand dispersal processes and their consequences over time (Wang \& Smith 2002). To this end, a number of studies have used cohort- or stand-specific analyses of plant spatial and genetic structures to work backwards and indirectly infer the postdispersal fates of plants (e.g. Barot et al. 1999; Kalisz et al. 2001; Chung et al. 2007; Fuchs \& Hamrick 2010). In addition, spatial analyses can also be used to investigate the fine-scale interactions among plant individuals as well as to account for potential confounding associations that may arise from habitat heterogeneity (Wiegand \& Moloney 2004). The use of both spatial and genetic information in tandem can thus strengthen our ability to investigate the consequences of seed dispersal on the spatial and genetic structures of long-lived plant species (Chung et al. 2007; Jacquemyn et al. 2009).

In this study, we investigated the consequences of frugivore-mediated seed dispersal on the spatial and genetic structures of a common canopy palm Attalea phalerata Mart. ex Spreng. Attalea spp. are among the largest and most abundant palms in tropical America (Henderson et al. 1995). They produce large-seeded fruits that are primarily rodent-dispersed (Forget et al. 1994; Wright \& Duber 2001). Seed dispersal is important for the regeneration of Attalea spp. because palm seeds experience intense distance-dependent mortality from the predation by bruchid beetles (Janzen 1971; Wright 1983; Forget et al. 1994; Silvius \& Fragoso 2002; Fragoso et al. 2003; Pimentel \& Tabarelli 2004). Rodents frequently scatter-hoard the seeds of Attalea spp. palms to microsites next to logs, horizontal liana stems on the ground and the buttress of heterospecific trees (Kiltie 1981; Silvius \& Fragoso 2003; Pimentel \& Tabarelli 2004; Bonjorne de Almeida \& Galetti 2007). Collectively, these studies suggest that the nonrandom dispersal of Attalea spp. seeds will generate distinct spatial patterns and genetic structures in a population. To examine these interactions, we used field experiments, molecular and spatial analytical studies to (i) characterize seed dispersal patterns and (ii) examine how contemporary local seed dispersal influences the recruitment patterns of seedlings with respect to other conspecifics by studying seedling neighbour composition, spatial associations, and genetic structures. We further employed cohort-specific analyses to (iii) infer the evolution of these patterns over time and to indirectly assess the long-term consequences of seed dispersal on palm population dynamics and genetics.

\section{Materials and methods}

\section{Study site and species}

This study was conducted in a 2.25-hectare plot $(150 \mathrm{~m} \times 150 \mathrm{~m})$ at the Cocha Cashu Biology Field Station (CC) in Manu National Park, Peru. Attalea phalerata is one of the most abundant species at CC (Gentry \& Terborgh 1990). This arboreal palm grows to about $25 \mathrm{~m}$ tall and produces large leaves than span $c .8 \mathrm{~m}$. A. phalerata is monoecious, but the staminate and pistillate inflorescence on individual palms flower asynchronously so the species is considered functionally dioecious (Anderson et al. 1988; Pintaud 2008). Palms within a population flower and fruit asynchronously. Weevils (Phyllotrox spp.), nitidulid beetles (Mystrops spp.) and bees (Trigona spp.) are the main pollinators (Anderson et al. 1988; Henderson et al. 2000; Voeks 2002; Núñez et al. 2005; Fava \& Covre 2011). The fruits are large ellipsoid drupes (mean length of $9.0 \pm 0.8 \mathrm{~cm}$ and diameter of $3.7 \pm 0.4 \mathrm{~cm}$ ) with a fleshy mesocarp surrounding a 'seed' (applied here to refer to the hard woody endocarp and the actual seed) (mean length of $8.2 \pm 0.8 \mathrm{~cm}$ and diameter of $3.4 \pm 0.5 \mathrm{~cm})$.

At Cocha Cashu, rodents and capuchins are among the most important dispersers of large-seeded palms (Cintra \& Horna 1997; J. Choo, unpublished). Capuchin monkeys are the primary dispersers (i.e. animals that remove seeds and fruits directly from a tree) of $A$. phalerata, but they only contribute to limited seed dispersal within a few metres of palm crowns. This is because 
capuchins cause large numbers of intact fruits to fall to the ground directly beneath fruiting palms when they forage for fruits in the crowns. Capuchins also restrict their feeding on palm fruits to branches adjacent to palm crowns and will discard the seeds to the ground before departing (Cintra \& Horna 1997; J. Choo, unpublished). Medium-sized rodents (squirrels-Sciurus spadiceus; agoutis-Dasyprocta variegata; and acouchis-Myoprocta pratti) are the secondary dispersers (i.e. animals that disperse seeds and fruits that have fallen to the ground) of A. phalerata (Cintra \& Horna 1997; J. Choo, unpublished). Seeds of $A$. phalerata that are not dispersed away from under parent palms suffer high mortality rates (c. $80 \%$ ) from subsequent predation by bruchid beetles (J. Choo, unpublished).

\section{Palm census and tissue collection}

We mapped and tagged all individuals of $A$. phalerata found in the study plot. To classify a palm as reproductive, we checked the crowns for evidence of old or emerging flower spadices and searched the ground under the palm canopies for old endocarps and flower spadices. We categorized each nonreproductive palm in the population as a seedling or one of the two juvenile cohorts. Seedlings $(S)$ possess entire leaves and are usually $<0.5 \mathrm{~m}$ tall. Juvenile palms possess pinnately divided leaves, and we grouped them into two subcategories consisting of juveniles not taller than $3.0 \mathrm{~m}$ (J1) and juveniles taller than $3.0 \mathrm{~m} \mathrm{(J2).}$ The exact ages of palms are difficult to determine so size categories served as proxies for the relative ages of palms.

\section{Seed-and fruit-dispersal experiments}

To characterize local patterns of seed dispersal and their relevance to conspecific palm interactions, we monitored the dispersal of 288 seeds and 324 fruits. We divided the plot into $36,25 \times 25 \mathrm{~m}$ subplots (i.e. $6 \times 6$ grid) each with two feeding stations spaced approximately $12.5 \mathrm{~m}$ apart. We obtained seeds and fruits from four different palm adults in the plot and allocated them randomly to feeding stations. Each feeding station was provisioned with four seeds and 4-5 fruits arranged alternately in a single circle. Seeds and fruits were each labelled and tagged with a nylon-line and a flagging tape attached to the end of the line to facilitate their recovery. All 72 feeding stations were established on the same day, and we revisited each of them daily for 3 weeks to measure seed or fruit dispersal distances and to document the characteristics of the microsites where they were found. We searched the entire plot including a 30-m buffer zone for missing seeds or fruits.
We calculated mean dispersal distances using only data from dispersed seeds and fruits.

\section{Parentage analysis}

We collected leaf samples for all seedling and juvenile palms and from the canopy leaves of all adults. DNA was extracted from approximately $100 \mathrm{mg}$ of silica-dried leaf tissues using a modified CTAB protocol (Doyle \& Doyle 1987). Adult and nonadult palms were genotyped using ten microsatellite loci developed for $A$. phalerata (Choo et al. 2010). Positive and negative controls were used to detect errors and contamination. We determined genotyping error rates by regenotyping approximately $15 \%$ of alleles (1600 of 10 800). Parent-offspring (maternal and paternal) relationships were reconstructed using CERVUS software (3.03; Kalinowski et al. 2007) under a maximum likelihood framework implemented in the program. This program estimates the likelihood of parentage at both relaxed $(80 \%)$ and strict $(95 \%)$ confidence intervals. We selected the $80 \%$ confidence for parentage assignment, although over $82 \%$ of the offspring were assigned to a single parent at a confidence of $95 \%$. We used 10000 simulation tests to calculate the critical likelihood values. For our analysis, we estimated the number of candidate parents (43) and the proportion sampled (0.69) using PASOS software (Duchesne et al. 2005), included genotyping error at 0.014 (based on assessments of genotyping error above) and proportion of loci typed at 1 (no missing genotypic data).

CERVUS is unable to distinguish maternal from paternal parent based on our markers, thus when CERvUs assigned two adults to an offspring, we assumed that the nearest adult was the maternal parent and the more distant palm the paternal parent. These assumptions were based on the average foraging distances of pollinators associated with $A$. phalerata, which range between 100 and $500 \mathrm{~m}$ (Mora-Urpí \& Solís-Fallas 1980; Heard 1999; Araújo et al. 2004; Franz 2006; Sezen et al. 2007). Pollen dispersal for $A$. phalerata is thus more likely to occur over larger distances than seed dispersal, estimated to be $25 \mathrm{~m}$ from field studies of other Attalea species (Forget 1990; Pimentel \& Tabarelli 2004; Bonjorne de Almeida \& Galetti 2007). Our assumptions could lead to more conservative estimates of seed dispersal and recruitment distances. We estimated mean seed dispersal distances using the euclidean distances between seedlings and their assigned maternal parent.

In addition to parentage methods, we applied the seedling neighbourhood model (SNM) to obtain population-level dispersal estimates (Burczyk et al. 2006; Chybicki \& Burczyk 2010). The SNM is a probabilistic method that uses both the spatial positions and the multilocus genotypes of seedling and parent generations to 
model the probability structure of the data within a specified neighbourhood. A maximum likelihood approach is then used to simultaneously estimate dispersal distances (Burczyk et al. 2006; Chybicki \& Burczyk 2010). For the SNM analysis, we considered all palm adults in the plot to be within a single neighbourhood for all seedlings and set genotyping errors at 0.014. All analyses were carried out using the software NM+ (Chybicki \& Burczyk 2010).

To further examine dispersal patterns, we decomposed the seedling population into two groups. The first group consisted of seedlings dispersed 'near' maternal parents (i.e. $<10 \mathrm{~m}$ ) and the second group included seedlings that were dispersed 'away' (i.e. more than $10 \mathrm{~m}$ ) from maternal parents. These maternal parents were identified from parentage analysis (see above). We then determined the composition of neighbours found within $5 \mathrm{~m}$ of each focal seedling and classified them as maternal siblings, locals or immigrants. Maternal siblings share the same maternal palm as a focal seedling. Local individuals do not share the same maternal palm as a focal seedling, and their maternal parents are found within the study plot. Immigrant individuals do not share the same maternal palm as a focal seedling, and their maternal parents are assumed to originate from palms outside of the study plot. To infer changes to neighbour composition over time, we also determined the composition of neighbours for larger palm cohorts using a wider radius of $10 \mathrm{~m}$ as a result of the lower neighbour abundance.

\section{Fine-scale spatial genetic structure}

We tested for fine-scale SGS within palm cohorts as well as the SGS between palm cohorts (e.g. seedlings and adults) using the kinship coefficient $F_{i j}$ (Loiselle et al. 1995). $F_{i j}$ measures pairwise changes in the relatedness among palms (either within the same cohort or between two different cohorts) over spatial distance. Standard errors of $F_{i j}$ were estimated using a jackknife procedure. To visualize SGS, we plotted the mean $F_{i j}$ between individuals at each distance interval $r$, that is, $\hat{F}(r)$ against distance $r$ (Vekemans \& Hardy 2004). We selected distance intervals following recommendations of Degen et al. (2001), Cavers et al. (2005) and Hardy \& Vekemans (2002). Each distance interval contained at least 100 pairwise comparisons (ranged 106-5917), included more than $50 \%$ participation of individuals and displayed small standard errors for the estimates of $F_{i j}$. Distance intervals for adult cohorts were 50, 80, 110 and $130 \mathrm{~m}$; intervals for cohort-pair A-J2 were 14, 20, $25,30,35,40,45,50,70,90,110$ and $130 \mathrm{~m}$; intervals for all other cohorts and cohort pairs were 10, 15, 20, 25, 30, 35, 40, 45, 50, 70, 90, 110 and $130 \mathrm{~m}$. Confidence intervals (95\%) were generated using 10000 permuta- tions of individual locations to test whether SGS departed significantly from zero (i.e. no SGS). The SPAGEDI software (Hardy \& Vekemans 2002) was used for the above analyses.

To infer how seed dispersal influenced genetic associations among seedling populations, we measured the within-cohort SGS for the pooled seedling population as well as the decomposed seedling population following Hampe et al. (2010). The decomposed seedling SGS included (i) the SGS among seedlings that were dispersed 'near' (i.e. $<10 \mathrm{~m}$ ) maternal palms, (ii) the SGS among seedlings dispersed 'away' (i.e. $>10 \mathrm{~m}$ ) from maternal palms and (iii) the SGS between pairs of seedlings dispersed 'near' and 'away' from maternal palms. Breaking down the within-cohort SGS of the seedling population into the three-component groups allows the relative contribution of each seedling group to the total SGS to be assessed (Hampe et al. 2010). We further measured the between-cohort SGS for seedlings and other palm cohorts (J1, J2, and A) to determine the influence of dispersal on their genetic associations. To examine the evolution of SGS, we assessed the change in the strength of the within-cohort SGS from the smallest to largest nonadult cohorts (i.e. S $\rightarrow \mathrm{J} 1 \rightarrow \mathrm{J} 2$ ) and the change in strength of the between-cohort SGS for adults and nonadult cohorts (i.e. A-S $\rightarrow$ A-J1 $\rightarrow$ A-J2)

In addition to SGS, we calculated the $S p$ statistic of Vekemans \& Hardy (2004) to facilitate comparisons of the strength of SGS found within and between cohorts. $S p$ was calculated across loci as $-b_{F} /[1-F(1)]$, where $b_{F}$ is the observed regression slope of $\hat{F}(r)$ on the logarithm of distance $r$, and $F(1)$ is the mean kinship coefficient between pairs of individuals found within the first-distance class interval. Behrens-Fisher test implemented in the $\mathrm{R}$ packaged npmc (Munzel \& Hothorn 2001) was used to test for significant differences in the $S p$ values within and between cohorts.

\section{Spatial analyses}

We used the univariate pair correlation function [PCF; $\left.g_{11}(r)\right]$ and the bivariate PCF $\left(g_{12}(r)\right)$ to investigate spatial associations among palm individuals within and between cohorts, respectively. PCF is defined by the number of points at distance $r$ from an arbitrary point divided by the density of the point pattern (Wiegand \& Moloney 2004). Like the kinship coefficient, PCF is not a cumulative function and allows the strength and range of spatial structure to be determined at specific distances $r$ (Wiegand et al. 2007). Observed values of $g_{11}(r)$ or $g_{12}(r)$ were compared against the Monte Carlo envelopes of point data simulated under two null models (see below) that also accounted for environmental heterogeneity (Wiegand \& Moloney 2004). We used the 25th highest 
and lowest values of 999 simulations to construct the envelopes following Wiegand et al. (2007). Significant positive or negative spatial associations were additionally determined using a goodness-of-fit test when values of $g_{11}(r)$ or $g_{12}(r)$ fell above or below the simulations envelopes, respectively (Diggle 1985; Wiegand et al. 2007). All spatial analyses were carried out with the software Programita (Wiegand \& Moloney 2004).

We examined spatial associations within cohorts (univariate PCF) using the heterogeneous Poisson null model (Wiegand \& Moloney 2004). The heterogeneous Poisson null model allowed us to investigate (i) the implications of dispersal on nonrandom associations among all seedlings and among seedlings dispersed 'near' and 'away' from maternal palms and (ii) the evolution of spatial associations among nonadult palms from the seedling to J2 cohort (i.e. S $\rightarrow \mathrm{J} 1 \rightarrow \mathrm{J} 2$ ). The antecedence null model was used to examine spatial associations among palms in two different cohorts (bivariate PCF). This model accounted for the fact that the point pattern 1 (e.g. adults) may be present in the system before pattern 2 (e.g. seedlings) (Wiegand \& Moloney 2004). We used the antecedent null model to detect (i) nonrandom associations between seedlings and larger palm cohorts (J1, J2, and A) that may arise as a consequence of seed dispersal and (ii) evolution in the spatial associations between adults and nonadult cohorts (i.e. A-S $\rightarrow$ A-J1 $\rightarrow$ A-J2).

For all within- and between-cohort groups, we also calculated the mean $g(r)$ over distance $r$ to facilitate comparisons of the strength of small-scale spatial structure. We used a distance interval between 0 and $15 \mathrm{~m}$ to calculate mean $g(r)$ as this interval was comparable in scale to the first-distance class interval used for estimating the strength of genetic structure (i.e. $S p$ statistic). Significant differences in mean $g(r)$ within and between cohorts were tested using the Behrens-Fisher test (Munzel \& Hothorn 2001).

\section{Results}

\section{Palm census}

We identified and mapped a total of 540 palms in our study plot (Fig. 1). The population comprised of 30 reproductive adults (A), 202 seedlings (S), 154 juveniles between 0 and $3 \mathrm{~m}$ tall (J1) and 154 juveniles taller than $3 \mathrm{~m}(\mathrm{~J} 2)$.

\section{Seed-and fruit-dispersal experiments}

We found only 30\% of tagged fruits (96) and 20\% of tagged seeds (58). The majority of seeds and fruits were recovered $(98 \%)$ within the study plot, while $2 \%$ were

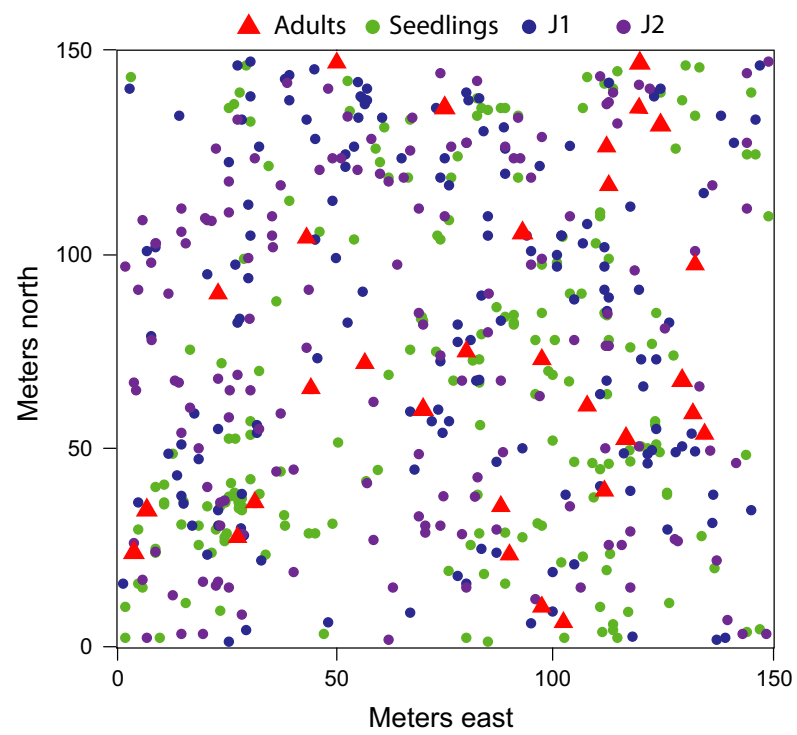

Fig. 1 Distribution of Attalea phalerata in the $150 \times 150-\mathrm{m}$ plot in Cocha Cashu. Palm adults are shown as red triangles. Seedlings, J1 and J2 cohorts are shown as green, blue and purple circles, respectively.

recovered outside of plot boundaries. Seeds and fruits were dispersed to microhabitats near fallen logs, at the bases of tree trunks and in dense under-story cover of fallen twigs and vines. Tagged A. phalerata fruits were also variously codispersed to the same microsites on four occasions and codispersed near Astrocaryum murumuru palm seeds on ten occasions. The mean dispersal distance for both seeds and fruits combined was $5.8 \pm 8.6 \mathrm{~m}$. Dispersal distances for seeds averaged $3.4 \pm 3.5 \mathrm{~m}$ (range $0.3-23 \mathrm{~m}$ ) and was significantly shorter than the dispersal distances for fruits, which averaged $7.3 \pm 8.5 \mathrm{~m}$ (range 0.2-70.6 m; Wilcoxon rank sum test, $W=4028$, $P<0.001)$. Frequency distribution of dispersal distances indicated that more than $99 \%$ of seeds and fruits were dispersed $<30 \mathrm{~m}$ from feeding stations (Fig. 2A).

\section{Parentage analysis}

A total of 292 nonadult palms (57.2\%) in the study plot were assigned to a maternal parent, while 59 nonadult palms $(11.6 \%)$ were assigned to a pair of parents (maternal and paternal). The remaining 159 nonadult palms $(31.2 \%)$ were not assigned to any parents in the study plot. Among the seedling population, a total of 144 seedlings $(71.3 \%)$ were assigned to a maternal parent, $33(16.3 \%)$ were assigned to a pair of parents, while $25(12.4 \%)$ were not assigned to any parents in the plot. As there was no evidence of recently demised adult palms, we assumed the seedlings that were not assigned to any parents originated from parents outside of the study plot (i.e. immigrants). 

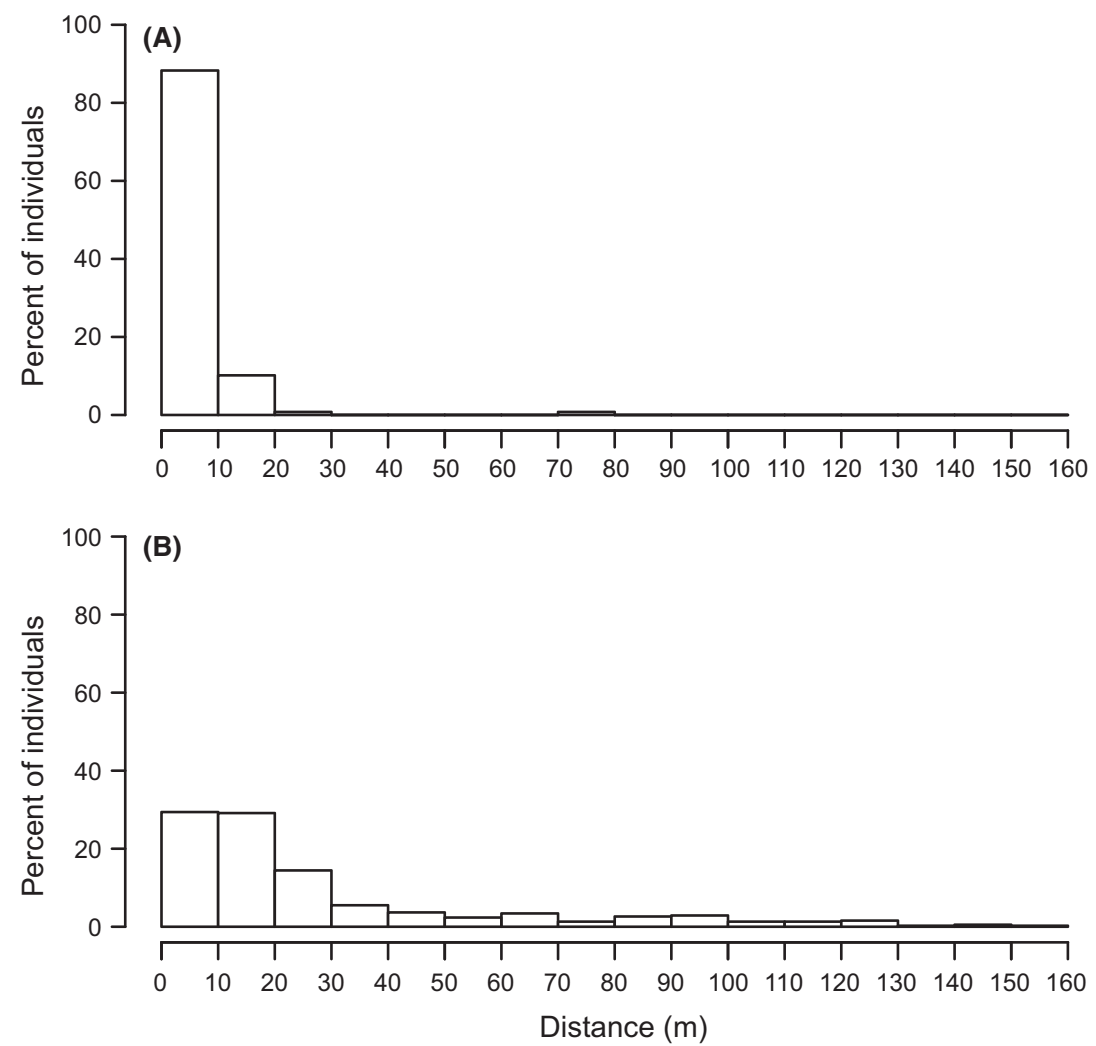

Fig. 2 The frequency distribution of dispersal distances based on estimates from seed-and fruit-tagging experiments (A) and estimates from the recruitment distances of genotyped seedlings from maternal palms (B).
The mean dispersal distance of palm offspring based on the recruitment distance of the 144 seedlings that were assigned to maternal parents in the plot was $23.8 \pm 29.7 \mathrm{~m}$ (1-156.4 m). Approximately $73 \%$ of genotyped seedlings were dispersed within $30 \mathrm{~m}$ of their maternal parent (Fig. 2B). Mean dispersal distances estimated using the SNM was $20.5 \mathrm{~m}$.

Seedlings dispersed 'near' maternal palms were associated with seedling neighbours that comprised on average of $58.5 \%$ maternal siblings and $41.5 \%$ of both locals and immigrants. Seedlings dispersed 'away' from maternal parents were associated with seedling neighbours that consisted on average of $33.3 \%$ maternal siblings and $66.7 \%$ of both locals and immigrants (Table 1A). The proportion of maternal sibling neighbours decreased by more than threefold for palms in the J1 or J2 cohort (Table 1A). Similarly, adult palms were associated with three times lower the proportion of maternal offspring neighbours in the $\mathrm{J} 2$ cohort than those in the seedling cohort (i.e. S-A > J1-A > J2-A; Table 1B).

\section{Spatial genetic structure}

SGS among seedlings and between seedling and other cohorts. In general, pairwise comparisons among palm neighbours indicated that there was significant SGS
$(<30 \mathrm{~m})$ for palms within and between cohorts with the exception of the cohort-pair seedling and J2. Focusing on seedling cohort, the strength of SGS among seedlings was significantly higher than those found within J1 and J2 cohorts $(S p=0.034$; Behrens-Fisher test $P<0.001$; Table 1A, Fig. 3). This strong SGS resulted from positive kinship associations among the seedlings that were dispersed 'near' and 'away' from maternal palms $(S p=0.39$ and 0.24; Table 1A, Fig. 4). Seedlings also exhibited strong SGS with adults $(S p=0.049$, Table $1 \mathrm{~B}$, Fig. 5). SGS was relatively weaker between seedling and J1 cohort and was lost between seedling and J2 $(S p=0.014$ and 0.005, Table 1B, Fig. 5).

Evolution of SGS across cohorts and cohort pairs. The strength of the within-cohort SGS for nonadult palms decreased from the smallest to largest cohorts (S > J1 > J2) with Sp decreasing by threefold from 0.034 to 0.010 (Table 1A, Fig. 3). Similarly, the strength of the between-cohort SGS for adults and nonadults decreased by threefold from 0.049 to 0.016 (i.e. S-A > J1-A > J2-A) (Table 1B, Fig. 5).

\section{Spatial associations}

Spatial associations among seedlings and between seedling and other cohorts. In general, there were significant 


\begin{tabular}{llllll}
\hline Cohorts & $S p$ & Mean $g(r)$ & $\begin{array}{l}\text { Offspring/ } \\
\text { siblings (\%) }\end{array}$ & $\begin{array}{l}\text { Locals } \\
(\%)\end{array}$ & $\begin{array}{l}\text { Immigrants } \\
(\%)\end{array}$ \\
\hline \multicolumn{7}{l}{ (A) Associations among palms within each cohort } \\
S & $0.034^{*}$ & $2.55^{*}$ & 39.1 & 51.5 & 10.4 \\
S 'near' & $0.039^{*}$ & $6.90^{*}$ & 58.5 & 38.5 & 3.0 \\
S 'far' & $0.024^{*}$ & $1.42^{*}$ & 33.3 & 52.2 & 14.5 \\
J1 & $0.010^{*}$ & $1.45^{*}$ & 6.2 & 61.5 & 32.3 \\
J2 & $0.010^{*}$ & $1.27^{*}$ & 12.5 & 50.5 & 37 \\
A & $0.024^{*}$ & 0.96 & - & - & - \\
(B) Associations among palms in two different cohorts & & \\
S and J1 & $0.014^{*}$ & $1.52^{*}$ & 14.6 & 73.2 & 12.1 \\
S and J2 & 0.005 & $1.22^{*}$ & 14.9 & 72.3 & 12.7 \\
S and A & $0.049^{*}$ & $1.53^{*}$ & 31.2 & 54.1 & 14.7 \\
J1 and A & $0.033^{*}$ & $1.28^{*}$ & 13.9 & 56.7 & 29.4 \\
J2 and A & $0.016^{*}$ & 0.83 & 10.5 & 57.9 & 31.6 \\
\hline
\end{tabular}

Table 1 Results of the associations among palms within and between cohorts showing the strength of genetic structure (i.e. $S p$ ), spatial structure [i.e. mean $g(r)$ ] and average composition (\%) of neighbours for palm cohorts and cohort pairs. Neighbour composition comprised of maternal offspring or siblings, locals (i.e. palms originating from maternal palms in the plot) and immigrants (i.e. palms originating from maternal parents outside of the plot) and was estimated from a $10 \mathrm{~m}$ radius around a focal palm (5 $\mathrm{m}$ radius was used for seedlings)

$\mathrm{S}$, seedlings; J1, juveniles $\leq 3 \mathrm{~m}$; J2, juveniles $>3 \mathrm{~m}$; A, Adults.

$(*)$ indicates significant spatial or genetic structure among palms within a cohort or among palms in two different cohorts.
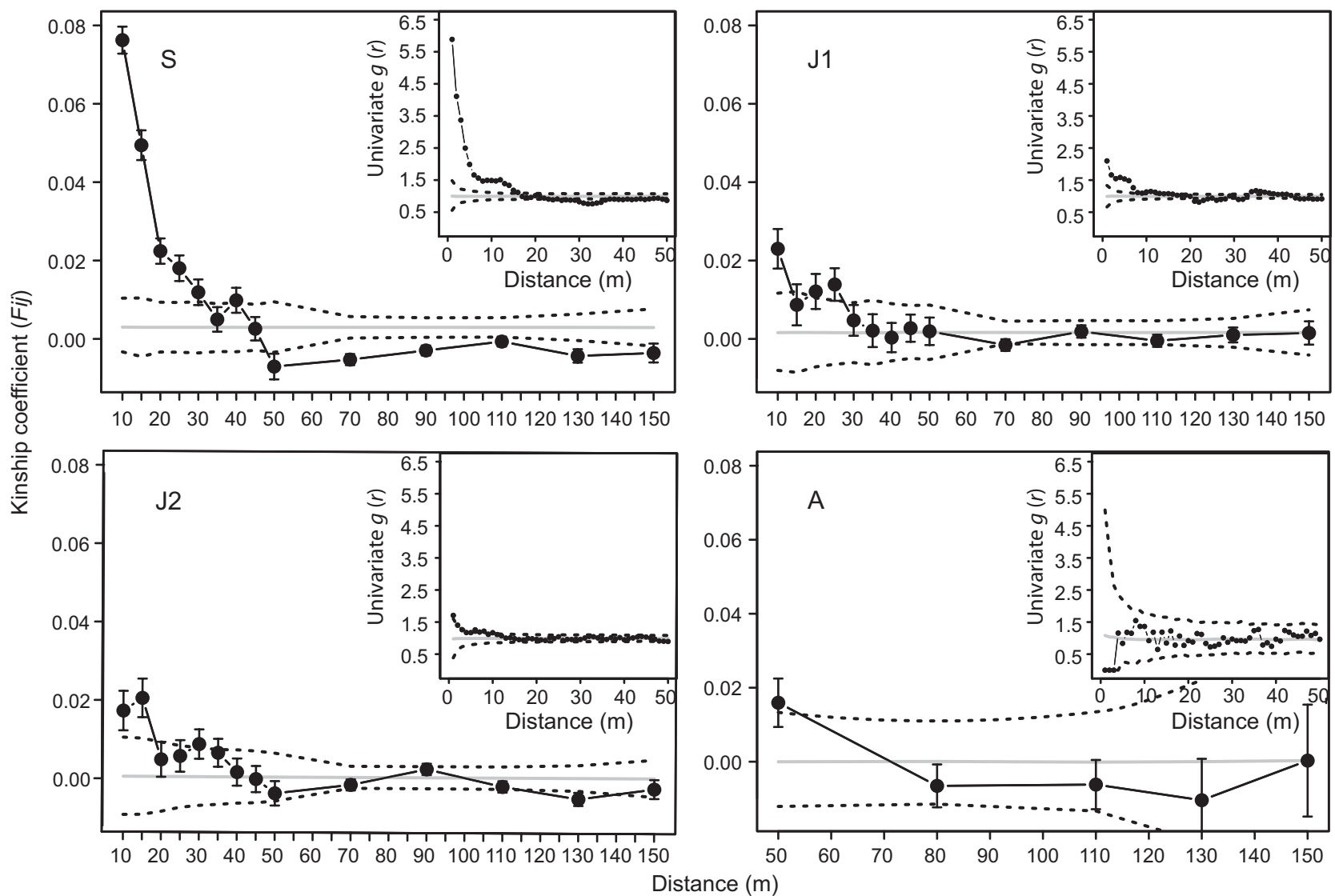

Fig. 3 The spatial genetic structure and spatial associations (inset) of palms within each cohort (solid lines). Grey lines show the expected values of the null models. Broken lines indicate the upper and lower permutation/simulation envelopes.

positive spatial associations at small scales $(<20 \mathrm{~m}$; $P<0.05)$ for palms within and between cohorts with the exception of the adult cohort, and the cohort pairs adult and J2, and J1 and J2. Seedlings were aggregated at small scales $(0-15 \mathrm{~m})$, and the strength of the spatial structure was significantly greater than those found in 


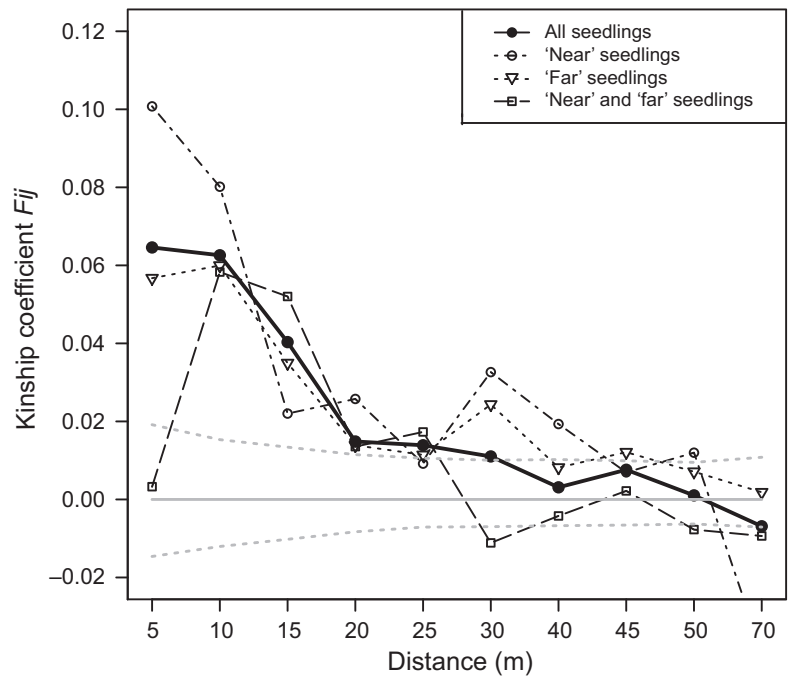

Fig. 4 The spatial genetic structure of the pooled seedling population (closed circles), seedlings dispersed 'near' maternal parents (i.e. $<10 \mathrm{~m}$ ) (open circles), seedlings dispersed 'far' from maternal parents (i.e. $>10 \mathrm{~m}$ ) (open triangle) and between pairs of seedlings 'near' and 'far' from maternal parents (open squares). Grey lines show the expected values of the null model. Broken lines indicate the upper and lower permutation envelopes.

J1 or J2 cohorts (mean $g(r)=2.55$; Behrens-Fisher test $P<0.001$; Table 1A, Fig. 3). This strong spatial structure resulted from aggregated patterns among seedlings dispersed 'near' and 'away' from maternal parents. However, the strength of the spatial structure among seedlings 'near' maternal parents was over three times greater than the 'far' seedlings with mean $g(r)=6.9$ and 1.4 respectively (Table $1 \mathrm{~A}$ ). The test of antecedence also indicated that seedlings were aggregated at small scales $(0-15 \mathrm{~m})$ with conspecific adults as well as with juveniles in the $\mathrm{J} 1$ and $\mathrm{J} 2$ cohort (Table 1B, Fig. 5).

Evolution of spatial associations across cohorts and cohort pairs. The strength of spatial structure among palms decreased from the smallest to largest cohort ( $\mathrm{S}>\mathrm{J} 1>\mathrm{J} 2$ ) with mean $g(r)$ decreasing threefold from 2.55 to 1.27 (Table 1A, Fig. 3). Spatial aggregation was strongest among palms in the adult and seedling cohort pair, positive but weaker for adult and J1 cohort-pair and was lost in adult and J2 cohort-pair (S-A > J1A > J2-A; mean $g(r)$ decreased from 1.53 to 0.083 ; Table 1B, Fig. 5).

\section{Discussion}

\section{Seed dispersal and seedling spatial and genetic patterns}

Frugivore seed dispersers played an important role in the recruitment distances of $A$. phalerata seedlings and their spatial associations with other conspecifics. Dispersal distances estimated from field experiments (seeds: $3.4 \mathrm{~m}$, fruits: $7.3 \mathrm{~m}$ ) suggest that frugivores moved the majority of palm seeds and fruits over short distances and within $30 \mathrm{~m}$ of feeding stations. Our findings are therefore in agreement with the dispersal distances documented for other Attalea species (Forget et al. 1994; Pimentel \& Tabarelli 2004) as well as other rodent-dispersed tropical tree species including Bertholletia excelsa Hymenea coubaril and Vouacaoupa americana (Hallwachs 1986; Forget 1990; Forget et al. 1994; Haugaasen et al. 2010). Because $A$. phalerata seeds and fruits are relatively large and heavy, medium to large rodents commonly found at Cocha Cashu including squirrels, agoutis, pacas, and acouchis are probably responsible for the small proportion of seeds and fruits that were dispersed over longer distances (>30 m) (Iob \& Vieira 2008).

However, comparisons between field and molecular methods highlighted a discrepancy in the mean and distribution of dispersal distances. Both parentage analysis and the seedling neighbourhood model estimated mean seed dispersal distance between 20 and $23 \mathrm{~m}$, which was considerably larger than estimates from seed- and fruit-tracking experiments (c. $6 \mathrm{~m})$. Moreover, parentage analysis found higher frequencies $(21 \%)$ of dispersal occurring more than $30 \mathrm{~m}$ from maternal palms compared to field estimates $(1 \%)$. Several factors may have contributed to this discrepancy. Our field experiments experienced low recovery rates $(30 \%)$ of seeds and fruits likely due to their dispersal into tree holes, ground holes or beyond our search area. A number of tags were recovered without their dispersed seeds or fruits. It is also possible that the tagging of seeds and fruits may have deterred or hindered the secondary dispersal of these palm propagules. The locations where artificial feeding stations were established could have influenced the frequency distribution of dispersal distances documented as the behaviours of seed dispersers including rodents are influenced by the distribution of reproductive trees and their fecundities (Jansen et al. 2004; Robledo-Arnuncio \& Garcia 2007).

On the other hand, assumptions used in our parentage analysis could have biased estimates of dispersal distances. Because our markers did not allow us to distinguish between paternal or maternal parents, we used the conservative approach of assuming the closest parent as the maternal palm based on available information suggesting pollen dispersal in general occurs over longer distances than seed dispersal (see methods). Further biases in dispersal estimates could have arisen from errors in parentage assignments. Although the markers used in this study had a high combined exclusion probability of 0.998 and should provide considerable power for parentage assignments (Choo et al. 

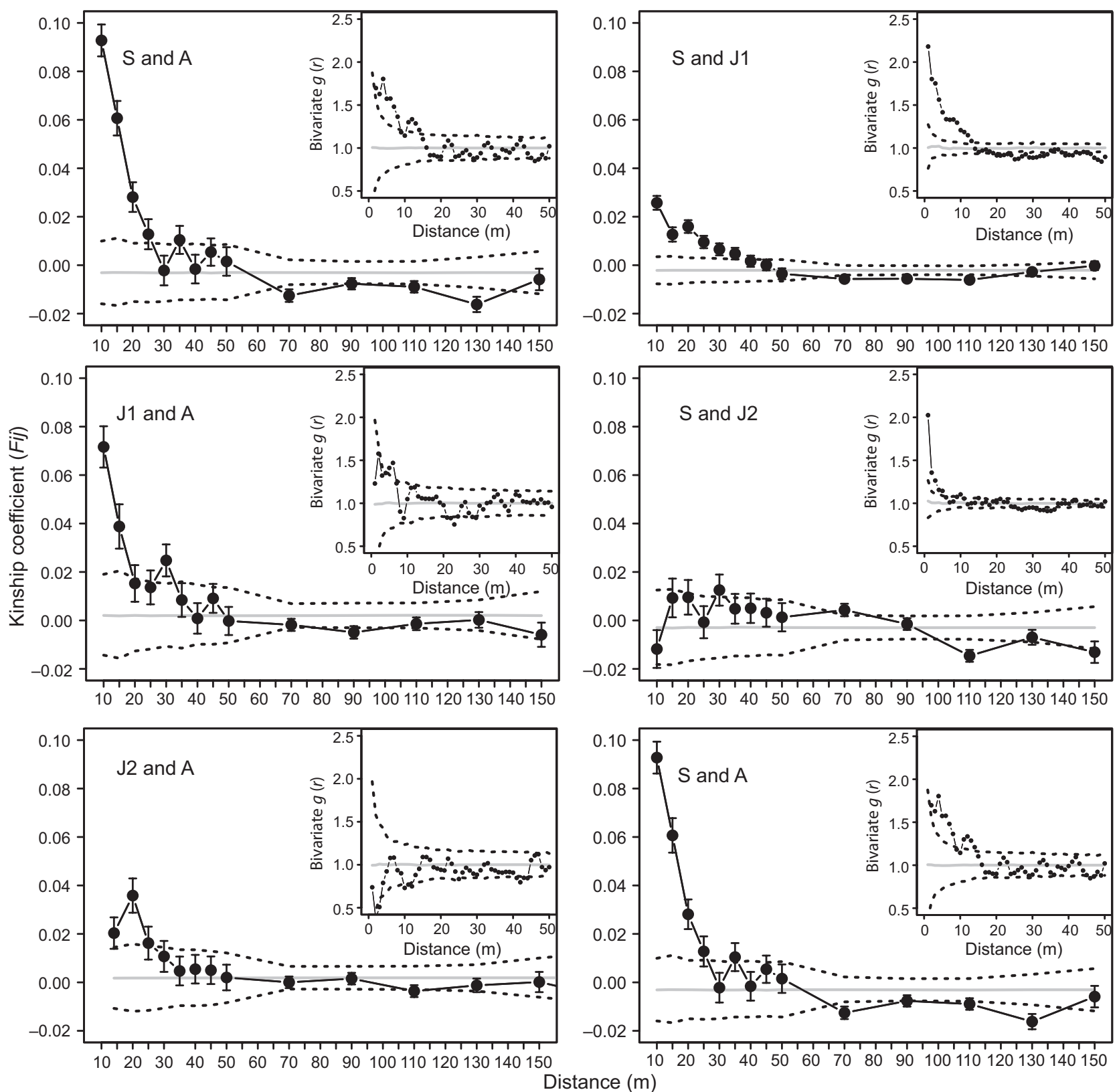

Fig. 5 The spatial genetic structure and spatial associations (inset) among palms between two different cohorts. Left column shows the between-cohort associations for adults and nonadults. Right column shows the between-cohort associations for seedlings and larger palm cohorts. Grey lines show the expected values of the null models. Broken lines indicate the upper and lower permutation/simulation envelopes.

2010), common problems including scoring errors, nonunique parental multilocus genotypes and the presence of family members other than parents in the population can still lead to assignment failures or wrong assignments (Jones \& Ardren 2003; Jones et al. 2005; Jones \& Muller-Landau 2008).

Despite the limitations of the field and molecular studies, both methods support that a large proportion of A. phalerata seeds was locally dispersed and recruited within a relatively small neighbourhood. Seed dispersal thus plays an important role in the local interactions among conspecific palms of this study population. Although, both methods support the occurrence of longer distance seed dispersal (>100 m), the extent and implications of this cannot be fully examined under the scale of the present study.

The neighbour composition, spatial and genetic structures of the decomposed seedling populations bore 
signatures of the seed dispersal behaviours of $A$. phalerata dispersers. The 'near' seedlings (i.e. seedlings found $<10 \mathrm{~m}$ from their genotyped maternal palms) were associated with a relatively high proportion of neighbours that were maternal siblings $(58.5 \%)$ and exhibited strong spatial and genetic structures that likely resulted from the short-distance dispersal of seeds from maternal palms by capuchins and rodents. Significant spatial and genetic structures as well as the associations of a relatively high proportion of sibling neighbours (33.3\%) among 'far' seedlings (i.e. seedlings found $>10 \mathrm{~m}$ from their genotyped maternal palms) indicated that seed dispersers were codispersing seeds to the same local neighbourhoods. Such seed dispersal patterns were also observed in our field experiments where a small sample of seeds was codispersed to the same microsites. There was evidence that seeds were dispersed to same microsites over successive fruiting periods based on the strong aggregation between seedlings and juveniles in the J1 and J2 cohorts. These dispersal and recruitment patterns were probably generated by rodent seed dispersers. Rodents are central place foragers, which means they usually forage in and disperse seeds to microsites or neighbourhoods near their nests or fruiting trees (Forget 1990; Aliaga-Rossel et al. 2008). In addition, differential survival of palm recruits at these microsites may further promote positive spatial and genetic structures among dispersed A. phalerata seedlings and between palm cohorts. At Cocha Cashu, peccaries can cause high mortality and influence recruitment patterns among seedlings through seed predation and their trampling and rooting activities. Silman et al. (2003) found that seedlings of a sympatric palm Astrocaryum murumuru established randomly in the absence of peccaries. In the presence of peccaries, however, seedlings established nonrandomly at locations that included rodent cache sites (e.g. near roots or logs) where they were protected from peccary activities. Attalea phalerata recruits may similarly experience differential survival at rodent cache sites, which can contribute to patterns of aggregation among dispersed seedlings and between seedlings and the two juvenile cohorts.

Local seed dispersal dynamics was also an important contributor to the significant spatial and genetic associations between seedlings and adult palms. Significant SGS between seedlings and adults was detectable up to c. $30 \mathrm{~m}$, which corresponded with the range of distances where the majority of seeds and seedlings were dispersed (99\% of seeds; $73 \%$ of seedlings). Parentage analysis indicated that a small proportion of local and immigrant seedlings $(12.4 \%)$ contributed to the aggregated spatial patterns between adult palms and seedlings. These associations between seedlings and nonmaternal palms could arise from rodents moving seeds or fruits away from fruiting palms and burying them near other adult palms to facilitate relocation as well as to prevent competitors from finding these resources (Jansen et al. 2004; Pimentel \& Tabarelli 2004; Galvez et al. 2009). In addition, seed burial has been shown to contribute to the survival of seeds near conspecific trees because they are protected against the predatory activities of bruchid beetles (Smythe 1989).

\section{Evolution of spatial and genetic structure}

In general, changes in the spatial and genetic structures within and between palm cohorts suggest that distanceand density-dependent mortality were probably important processes affecting this palm population following dispersal and seedling recruitment. Strong aggregation between adults and seedlings suggests that seedlings initially experienced relatively weak distance-dependent mortality. However, the weaker spatial structure between adults and J1 cohort and subsequent loss of spatial structure between adults and J2 cohort indicated the onset of strong negative distance-dependent interactions between adults and juveniles over time. Distantdependent interactions also appear to have had a stronger impact on offspring than nonoffspring counterparts. The proportion of offspring neighbours recruiting near maternal palms decreased by threefold from the seedling to J2 cohort, whereas the proportion of nonoffspring neighbours remained relatively constant from the seedling to J2 cohort. These patterns suggest that offspring recruiting near maternal palms may experience higher mortality and lower likelihood of reaching reproductive age than their nonoffspring counterparts. Augspurger \& Kelly (1984) have similarly found that seedlings of Platypodium elegans recruiting under maternal trees experienced higher mortality than those that established near other conspecific adults. Such patterns of mortality could result from pathogens causing greater mortality among offspring than nonoffspring propagules recruiting near parental trees (Augspurger \& Wilkinson 2007).

Changes in the spatial and genetic patterns across nonadult cohorts were consistent with negative densitydependent interactions and mortality among palm conspecifics. The progressive decrease in the strength of positive spatial structure among palms from seedling to adult cohorts suggests larger palms experienced stronger negative plant-plant interactions over time. Density-dependent mortality also appear to have had a greater impact on neighbours that were close relatives based on the weaker SGS and lower proportion of sibling neighbours associated with palms in larger cohorts. Similar erosion in the SGS among plants in larger 
cohorts has also been documented in other tropical trees species (e.g. Hardesty et al. 2005), and studies suggest that selection against inbred individuals may be involved (Hamrick et al. 1993a; Epperson \& AlvarezBuylla 1997). The decrease in the strength of withincohort SGS from small to large nonadults was, however, incongruent with the relatively strong SGS observed in the adult cohort. As SGS in the adult cohort was estimated from a relatively small sample population of 30 individuals, we suspect the estimates may not be accurate.

In summary, the findings of this study highlight that seed dispersers play an important role in maintaining the aggregated distribution and genetic associations of A. phalerata palms at Cocha Cashu. Our work suggests that these associations contribute to postdispersal distance- and density-dependent mortality of this dominant palm and may prevent them from forming monospecific stands. Differential mortality among closely aggregated maternal palm relatives are likely to influence the genetic diversity of palms in this population over time although further studies will be necessary to confirm this. We conclude from this study that disruptions to palm-frugivore seed disperser interactions and the cascading consequences thereafter will probably have severe implications for the spatial and genetic structures of this palm population.

\section{Acknowledgements}

We thank C. Carasco for her assistance with the fieldwork, and M. Foster and V. Swamy for logistical support in the field. We thank S. Boles, J. Godoy, H. Ishak, P. Jordano, and T. Wayne for their assistance and technical advice for the laboratory work. We are grateful to T. Wiegand for his support with Programita. We thank E. Economo and three anonymous reviewers for their insightful comments and suggestions. JC was funded by the Lindbergh Foundation, the University of Texas at Austin and the Organization for Tropical Studies. We thank the Instituto Nacional de Recursos Naturales (INRENA), Peru, for their permission to conduct the field research in Manu National Park.

\section{References}

Aliaga-Rossel E, Kays RW, Fragoso JMV (2008) Home-range use by the Central American agouti (Dasyprocta punctata) on Barro Colorado Island, Panama. Journal of Tropical Ecology, 24, 367-374.

Anderson AB, Overal WL, Henderson A (1988) Pollination ecology of a forest-dominant palm (Orbignya phalerata Mart.) in Northern Brazil. Biotropica, 20, 192-205.

Araújo ED, Costa M, Chaud-Netto J et al. (2004) Body size and flight distance in stingless bees (Hymenoptera: Meliponini): inference of flight range and possible ecological implications. Brazilian Journal of Biology, 64, 563-568.
Augspurger CK, Kelly CK (1984) Pathogen mortality of tropical tree seedlings: experimental studies of the effects of dispersal distance, seedling density, and light conditions. Oecologia, 61, 211-217.

Augspurger CK, Wilkinson HT (2007) Host specificity of pathogenic Pythium species: implications for tree species diversity. Biotropica, 39, 702-708.

Bagchi R, Press MC, Scholes JD (2010) Evolutionary history and distance dependence control survival of dipterocarp seedlings. Ecology letters, 13, 51-59.

Barot S, Gignoux J, Menaut JC (1999) Demography of a savanna palm tree: predictions from comprehensive spatial pattern analyses. Ecology, 80, 1987-2005.

Bonjorne de Almeida L, Galetti M (2007) Seed dispersal and spatial distribution of Attalea geraensis (Arecaceae) in two remnants of Cerrado in Southeastern Brazil. Acta Oecologica, 32, 180-187.

Burczyk J, Adams WT, Birkes DS et al. (2006) Using genetic markers to directly estimate gene flow and reproductive success parameters in plants on the basis of naturally regenerated seedlings. Genetics, 173, 363-372.

Cavers S, Degen B, Caron H et al. (2005) Optimal sampling strategy for estimation of spatial genetic structure in tree populations. Heredity, 95, 281-289.

Choo J, Ishak H, Simpson BB et al. (2010) Characterization of 14 microsatellite loci of a tropical palm Attalea phalerata. American Journal of Botany, 97, 105-106.

Chung MY, Nason JD, Chung MGI (2007) Effects of population succession on demographic and genetic processes: predictions and tests in the daylily Hemerocallis thunbergii (Liliaceae). Molecular ecology, 16, 2816-2829.

Chybicki IJ, Burczyk J (2010) NM+: software implementing parentage-based models for estimating gene dispersal and mating patterns in plants. Molecular Ecology Resources, 10, 1071-1075.

Cintra R, Horna V (1997) Seed and seedling survival of the palm Astrocaryum murumuru and the legume tree Dipteryx micrantha in gaps in Amazonian forest. Journal of Tropical Ecology, 13, 257-277.

Clark CJ, Poulsen JR, Connor EF et al. (2004) Fruiting trees as dispersal foci in a semi-deciduous tropical forest. Oecologia, 139, 66-75.

Clark CJ, Poulsen JR, Bolker BM et al. (2005) Comparative seed shadows of bird-, monkey-, and wind-dispersed trees. Ecology, 86, 2684-2694.

Comita LS, Hubbell SP (2009) Local neighborhood and species' shade tolerance influence survival in a diverse seedling bank. Ecology, 90, 328-334.

Connell JH (1971) On the role of natural enemies in preventing competitive exclusion in some marine animals and in rain forest trees. In: Dynamics of Populations (eds Boer den PJ and Gradwell GR), pp. 298-312. Pudoc, Waginengin.

Degen B, Caron H, Bandou E et al. (2001) Fine-scale spatial genetic structure of eight tropical tree species as analysed by RAPDs. Heredity, 87, 497-507.

Diggle PJ (1985) A kernel method for smoothing point process data. Applied Statistics (Journal of the Royal Statistical Society, Series C), 34, 138-147.

Doyle J, Doyle JL (1987) Genomic plant DNA preparation from fresh tissue-CTAB method. Phytochemical Bulletin, 19, 11-15. 
Duchesne P, Castric T, Bernatchez L (2005) PASOS (parental allocation of singles in open systems): a computer program for individual parental allocation with missing parents. Molecular Ecology Notes, 5, 701-704.

Epperson BK, Alvarez-Buylla ER (1997) Limited seed dispersal and genetic structure in life stages of Cecropia obtusifolia. Evolution, 51, 275-282.

Fava WS, Covre WdS (2011) Attalea phalerata and Bactris glaucescens (Arecaceae, Arecoideae): phenology and pollination ecology in the Pantanal, Brazil. Flora-Morphology, Distribution, Functional Ecology of Plants, 206, 575-584.

Forget PM (1990) Seed-dispersal of Vouacapoua americana (Caesalpiniaceae) by caviomorph rodents in French Guiana. Journal of Tropical Ecology, 6, 459-468.

Forget PM, Munoz E, Leigh Jr EG (1994) Predation by rodents and bruchid beetles on seeds of Scheelea palms on Barro Colorado Island, Panama. Biotropica, 26, 420-426.

Forget PM, Mercier F, Collinet F (1999) Spatial patterns of two rodent-dispersed rain forest trees Carapa procera (Meliaceae) and Vouacapoua americana (Caesalpiniaceae) at Paracou, French Guiana. Journal of Tropical Ecology, 15, 301-313.

Fragoso JMV, Silvius KM, Correa JA (2003) Long-distance seed dispersal by tapirs increases seed survival and aggregates tropical trees. Ecology, 84, 1998-2006.

Franz NM (2006) Towards a phylogenetic system of derelomine flower weevils (Coleoptera: Curculionidae). Systematic Entomology, 31, 220-287.

Fuchs EJ, Hamrick J (2010) Spatial genetic structure within size classes of the endangered tropical tree Guaiacum sanctum (Zygophyllaceae). American Journal of Botany, 97, 1200-1207.

Galvez D, Kranstauber B, Kays RW (2009) Scatter hoarding by the Central American agouti: a test of optimal cache spacing theory. Animal Behaviour, 78, 1327-1333.

Gentry AG, Terborgh J (1990) Composition and dynamics of the Cocha Cashu "mature" floodplain forest. In: Four Neotropical Rainforests (ed. Gentry AG), pp. 542-564. Yale University Press, New Haven, Connecticut.

Hallwachs W (1986) Agoutis (Dasyprocta punctata), the inheritors of guapinol (Hymenaea courbaril: Leguminosae). In: Frugivores and Seed Dispersal (eds Estrada A and Fleming TH), pp. 285-304. W. Junk Publishers, Dordrecht.

Hampe A, El Masri L, Petit RJ (2010) Origin of spatial genetic structure in an expanding oak population. Molecular Ecology, 19, 459-471.

Hamrick JL, Murawski DA, Nason JD (1993) The influence of seed dispersal mechanisms on the genetic structure of tropical tree populations. Plant Ecology, 107, 281-297.

Hardesty BD, Dick CW, Kremer A et al. (2005) Spatial genetic structure of Simarouba amara Aubl. (Simaroubaceae), a dioecious, animal-dispersed neotropical tree, on Barro Colorado Island, Panama. Heredity, 95, 290-297.

Hardy OJ, Vekemans X (2002) SPAGeDi: a versatile computer program to analyse spatial genetic structure at the individual or population levels. Molecular Ecology Notes, 2, 618-620.

Hardy OJ, Maggia L, Bandou E et al. (2006) Fine-scale genetic structure and gene dispersal inferences in 10 Neotropical tree species. Molecular Ecology, 15, 559-571.

Harms KE, Wright SJ, Calderón O et al. (2000) Pervasive density-dependent recruitment enhances seedling diversity in a tropical forest. Nature, 404, 493-495.
Haugaasen JMT, Haugaasen T, Peres CA et al. (2010) Seed dispersal of the Brazil nut tree (Bertholletia excelsa) by scatterhoarding rodents in a central Amazonian forest. Journal of Tropical Ecology, 26, 251-262.

Heaney LR, Thorington Jr RW (1978) Ecology of neotropical red-tailed squirrels, Sciurus granatensis, in the Panama Canal Zone. Journal of Mammalogy, 59, 846-851.

Heard TA (1999) The role of stingless bees in crop pollination. Annual Review of Entomology, 44, 183-206.

Henderson A, Galeano G, Bernal R (1995) Field Guide to the Palms of the Americas. Princeton University Press, Princeton, New Jersey.

Henderson A, Fischer B, Scariot A et al. (2000) Flowering phenology of a palm community in a central Amazon forest. Brittonia, 52, 149-159.

Howe HF, Smallwood J (1982) Ecology of seed dispersal. Annual Reviews in Ecology and Systematics, 13, 201-228.

Iob G, Vieira EM (2008) Seed predation of Araucaria angustifolia (Araucariaceae) in the Brazilian Araucaria Forest: influence of deposition site and comparative role of small and 'large'mammals. Plant Ecology, 198, 185-196.

Jacquemyn H, Wiegand T, Vandepitte $\mathrm{K}$ et al. (2009) Multigenerational analysis of spatial structure in the terrestrial, food-deceptive orchid Orchis mascula. Journal of Ecology, 97, 206-216.

Jansen PA, Bongers F, Hemerik L (2004) Seed mass and mast seeding enhance dispersal by a neotropical scatter-hoarding rodent. Ecological Monographs, 74, 569-589.

Janzen DH (1970) Herbivores and the number of tree species in tropical forests. The American Naturalist, 104, 501-528.

Janzen DH (1971) The fate of Scheelea rostrata fruits beneath the parent tree: predispersal attack by bruchids. Principes, 15, 89-101.

Jones AG, Ardren WR (2003) Methods of parentage analysis in natural populations. Molecular Ecology, 12, 2511-2523.

Jones FA, Muller-Landau HC (2008) Measuring long-distance seed dispersal in complex natural environments: an evaluation and integration of classical and genetic methods. Journal of Ecology, 96, 642-652.

Jones FA, Chen J, Weng G et al. (2005) A genetic evaluation of seed dispersal in the neotropical tree Jacaranda copaia (Bignoniaceae). American Naturalist, 166, 543-555.

Kalinowski ST, Taper ML, Marshall TC (2007) Revising how the computer program CERVUS accommodates genotyping error increases success in paternity assignment. Molecular Ecology, 16, 1099-1106.

Kalisz S, Nason JD, Hanzawa FM et al. (2001) Spatial population genetic structure in Trillium grandiflorum: the roles of dispersal, mating, history, and selection. Evolution, 55, 1560-1568.

Karubian J, Sork VL, Roorda T et al. (2010) Destination-based seed dispersal homogenizes genetic structure of a tropical palm. Molecular Ecology, 19, 1745-1753.

Kiltie RA (1981) Distribution of palm fruits on a rain forest floor: why white-lipped peccaries forage near objects. Biotropica, 13, 141-145.

Levine JM, Murrell DJ (2003) The community-level consequences of seed dispersal patterns. Annual Review of Ecology, Evolution, and Systematics, 34, 549-574.

Loiselle BA, Sork VL, Nason J et al. (1995) Spatial genetic structure of a tropical understory shrub, Psychotria officinalis (Rubiaceae). American Journal of Botany, 82, 1420-1425. 
Metz M, Sousa W (2010) Widespread density-dependent seedling mortality promotes species coexistence in a highly diverse Amazonian rainforest. Ecology, 91, 3675-3685.

Mora-Urpí J, Solís-Fallas EM (1980) Polinización en Bactris gasipaes HBK (Palmae). Pollination of Bactris gasipaes HBK (Palmae). Revista de Biología Tropical, 28, 153-174.

Munzel U, Hothorn LA (2001) A unified approach to simultaneous rank test procedures in the unbalanced oneway layout. Biometrical Journal, 43, 553-569.

Nathan R, Muller-Landau HC (2000) Spatial patterns of seed dispersal, their determinants and consequences for recruitment. Trends In Ecology \& Evolution, 15, 278-285.

Núñez LA, Bernal R, Knudsen JT (2005) Diurnal palm pollination by mystropine beetles: is it weather-related? Plant Systematics and Evolution, 254, 149-171.

Peres CA, Baider C (1997) Seed dispersal, spatial distribution and population structure of Brazilnut trees (Bertholletia excelsa) in southeastern Amazonia. Journal of Tropical Ecology, 13, 595-616.

Pimentel DS, Tabarelli M (2004) Seed dispersal of the palm Attalea oleifera in a remnant of the Brazilian Atlantic Forest. Biotropica, 36, 74-84.

Pintaud JC (2008) An overview of the taxonomy of Attalea (Arecaceae). Revista Peruana de Biología, 15, 53-62.

Robledo-Arnuncio JJ, Garcia C (2007) Estimation of the seed dispersal kernel from exact identification of source plants. Molecular Ecology, 16, 5098-5109.

Russo SE, Augspurger CK (2004) Aggregated seed dispersal by spider monkeys limits recruitment to clumped patterns in Virola calophylla. Ecology Letters, 7, 1058-1067.

Sezen UU, Chazdon RL, Holsinger KE (2007) Multigenerational genetic analysis of tropical secondary regeneration in a canopy palm. Ecology, 88, 3065-3075.

Sezen UU, Chazdon RL, Holsinger KE (2009) Proximity is not a proxy for parentage in an animal-dispersed Neotropical canopy palm. Proceedings of the Royal Society B: Biological Sciences, 276, 2037-2044.

Silman MR, Terborgh JW, Kiltie RA (2003) Population regulation of a dominant rain forest tree by a major seed predator. Ecology, 84, 431-438.

Silvius KM, Fragoso JMV (2002) Pulp handling by vertebrate seed dispersers increases palm seed predation by bruchid beetles in the northern Amazon. Journal Of Ecology, 90, 10241032.

Silvius KM, Fragoso JMV (2003) Red-rumped agouti (Dasyprocta leporina) home range use in an Amazonian forest: implications for the aggregated distribution of forest trees. Biotropica, 35, 74-83.

Smythe N (1978) The natural history of the central American agouti. Smithsonian Contributions to Zoology, 257, 1-52.

Smythe N (1989) Seed survival in the palm Astrocaryum standleyanum: evidence for dependence upon its seed dispersers. Biotropica, 21, 50-56.

Snyder RE, Chesson P (2003) Local dispersal can facilitate coexistence in the presence of permanent spatial heterogeneity. Ecology Letters, 6, 301-309.
Swamy V, Terborgh JW (2010) Distance-responsive natural enemies strongly influence seedling establishment patterns of multiple species in an Amazonian rain forest. Journal of Ecology, 98, 1096-1107.

Terborgh J (1990) Seed and fruit dispersal-commentary. In: Reproductive Ecology of Tropical Forest Plants (eds Bawa KS and Hadley M), pp. 181-190. Parthenon Group, Paris.

Terborgh J, Nunez-Iturri G, Pitman NCA et al. (2008) Tree recruitment in an empty forest. Ecology, 89, 1757-1768.

Vekemans X, Hardy OJ (2004) New insights from fine-scale spatial genetic structure analyses in plant populations. Molecular Ecology, 13, 921-935.

Voeks RA (2002) Reproductive ecology of the piassava palm (Attalea funifera) of Bahia, Brazil. Journal of Tropical Ecology, 18, 121-136.

Wang BC, Smith TB (2002) Closing the seed dispersal loop. Trends In Ecology \& Evolution, 17, 379-386.

Wiegand T, Moloney KA (2004) Rings, circles, and null-models for point pattern analysis in ecology. Oikos, 104, 209-229.

Wiegand T, Gunatilleke S, Gunatilleke N (2007) Species associations in a heterogeneous Sri Lankan dipterocarp forest. The American Naturalist, 170, 77-95.

Wright SJ (1983) The dispersion of eggs by a bruchid beetle among Scheelea palm seeds and the effect of distance to the parent palm. Ecology, 64, 1016-1021.

Wright SJ, Duber HC (2001) Poachers and forest fragmentation alter seed dispersal, seed survival, and seedling recruitment in the palm Attalea butyraceae, with implications for tropical tree diversity. Biotropica, 33, 583-595.

J.C. is interested in plant dispersal ecology and understanding how seed dispersers influence plant gene flow, spatial patterns and species coexistence. T.E.J. is interested in phenotypic evolution and his research focuses on the interface of ecological and evolutionary processes in natural plant populations. B.B.S. is interested in the phylogeny and biogeography of angiosperms.

\section{Data accessibility}

Sample locations and microsatellite data: DOI: 10.5061/ dryad.bt473576. 